\title{
Wired on steroids: sexual differentiation of the brain and its role in the expression of sexual partner preferences
}

\author{
Brenda M. Alexander ${ }^{1}$, Donal C. Skinner ${ }^{2}$ and Charles E. Roselli ${ }^{3 *}$ \\ ${ }^{1}$ Department of Animal Science, University of Wyoming, Laramie, WY, USA \\ 2 Department of Zoology and Physiology, University of Wyoming, Laramie, WY, USA \\ ${ }^{3}$ Department of Physiology and Pharmacology, Oregon Health and Science University, Portland, OR, USA
}

\section{Edited by:}

Hubert Vaudry, University of Rouen, France

\section{Reviewed by:}

Micheal Baum, Boston University, USA

Robert James Handa, University of Arizona College of

Medicine - Phoenix, USA

*Correspondence:

Charles E. Roselli, Department of Physiology and Pharmacology L334, Oregon Health and Science

University, 3181 Sam Jackson Park Road, Portland, OR 97201-3098, USA. e-mail: rosellic@ohsu.edu
The preference to seek out a sexual partner of the opposite sex is robust and ensures reproduction and survival of the species. Development of female-directed partner preference in the male is dependent on exposure of the developing brain to gonadal steroids synthesized during critical periods of sexual differentiation of the central nervous system. In the absence of androgen exposure, a male-directed partner preference develops. The development and expression of sexual partner preference has been extensively studied in rat, ferret, and sheep model systems. From these models it is clear that gonadal testosterone, often through estrogenic metabolites, cause both masculinization and defeminization of behavior during critical periods of brain development. Changes in the steroid environment during these critical periods result in atypical sexual partner preference. In this manuscript, we review the major findings which support the hypothesis that the organizational actions of sex steroids are responsible for sexual differentiation of sexual partner preferences in select non-human species. We also explore how this information has helped to frame our understanding of the biological influences on human sexual orientation and gender identity.

Keywords: sexual orientation, sexual partner preference, sexually dimorphic nucleus, preoptic area, sexual differentiation, gonadal steroids

\section{INTRODUCTION}

Many behaviors in animals are sexually dimorphic and expressed preferentially or exclusively by one sex. For example, in the adult, testosterone does not reliably activate male-typical copulatory behaviors in female rodents and estrogen is unable to activate female-typical receptive behaviors in males. A large number of studies starting with the work of Phoenix et al. (1959) demonstrated in an array of animal species that these sex-related behaviors are influenced by hormones present during sensitive periods early in development when the brain is differentiating (Goy and Mcewen, 1980; Baum, 2006). Thus, testicular testosterone synthesis in male embryos is necessary not only for the development of internal and external genitalia but also predisposes the male to display male-typical behaviors and hormone responses later in life, a process referred to as masculinization. Lack of steroid hormone exposure predisposes animals to display female-typical adult sexual behaviors and hormone responses, a process referred to as feminization. Testosterone exposure not only masculinizes the brain but also actively defeminizes it so that in many species males are unable to exhibit female-typical behavioral responses, or exhibit a surge release in luteinizing hormone (LH) in response to increased estradiol. The developing male gonad also synthesizes Müllerian inhibiting hormone (MIH), which inhibits the development of the internal female reproductive tract and in mice may be involved in brain differentiation (Wang et al., 2009). The early actions of sex steroids are imperative for the maturation and/or organization of several brain structures and neural circuits. The differentiated neural circuits are then responsible for sex-typical responses following puberty when sex steroids are synthesized at adult levels by the mature gonad. Thus, it is common to refer to the permanent developmental effects of sex steroids as "organizational," while the reversible or transient effects observed during adulthood are referred to as "activational."

The most prominent and prevalent sex difference in behavior is sexual partner, or mate, preference. Most mating occurs between conspecific animals of different sexes. Same-sex courtship, mounting, and genital contact are phylogenetically widespread (Bagemihl, 1999; Vasey, 2002) and may be quite common in some species (e.g., bonobos), but the expression of same-sex behaviors does not imply a preference for same-sex partners. Sexual partner preferences are properly studied in conditions where animals are given a choice to sexually interact among different-sex stimuli, so that it is clear that the choice is sexually, and not socially, motivated. Studies in an array of animal species clearly demonstrate that sexual partner preferences are subject to both organizational and activational effects of gonadal steroid hormones (Bakker et al., 1996; Adkins-Regan et al., 1997; Baum, 2006; Henley et al., 2011). Although these studies are not entirely translatable to human sexuality, they represent a reasonable line of investigation that has guided investigators to search for possible origins of human sexual orientation through androgens and their target neural substrates. In its simplest conception, the theory that perinatal hormones determine sexual partner preference is predicated on the idea that like other aspects of gender, sexual preference is subject to natural variations in androgen exposure during a sensitive period of perinatal development. Thus, fetuses/neonates exposed to high levels 
of androgens during this period (mostly males) will be sexually attracted to females in adult life and fetuses/neonates exposed to low levels of androgens (mostly females) will be sexually attracted to males. There are abundant data showing that perinatal hormone manipulations in animals, especially rats (discussed below), lead to predicted changes in sexual partner preferences and coital performance. However, there are only a small number of species in which same-sex preferences, defined by choice tests, have been shown to occur spontaneously in unmanipulated populations. Of these, the domestic ram is the best studied and, as discussed later, provides some support for the idea that same-sex preferences are a manifestation of incomplete masculinization and defeminization.

Testosterone is unequivocally the primary gonadal steroid driving sexual differentiation and the development of sexual partner preference in male mammals. The effects of testosterone may be either direct and/or indirect, through its aromatase-derived estrogenic metabolites. However, there are several additional ways that hormone exposure may be responsible for atypical sexual partner preferences. Variations may relate to absolute levels of hormone, timing of exposure, metabolism to more or less active molecules, hormone receptor activity, availability of free as opposed to bound steroid, or some combination of these factors. Moreover, depending on the developmental timing of specific brain structures and their coincident exposure to the prevailing steroidal milieu, some brain structures may be demasculinized/defeminized, whereas others are not. In addition, the causes of variations could relate to individual genetic variability or exposure to environmental factors that suppress the reproductive axis (e.g., stress) or disrupt hormone actions (e.g., environmental endocrine disruptors; Ryan and Vandenbergh, 2002; Patisaul and Polston, 2008).

This manuscript will review major findings that support the hypothesis that the organizational actions of sex steroids are responsible for sexual differentiation of sexual partner preferences in select non-human species and explore how this work has informed and helped to frame our understanding of biological influences on human sexual orientation and gender identity.

\section{RATS}

Rats are the most studied model of sexual behavior and sexual partner preference. Not only is the rat an easily obtainable experimental animal, but it is born in an altricial state so that much of sexual differentiation of the brain occurs postnatally making it an easy model to manipulate experimentally. Testosterone-derived estrogen is the primary hormone driving brain differentiation in the rat. Development of female-directed partner preference in male rodents is independent of androgen receptor activation since both androgen insensitive rats (Tfm; Hamson et al., 2009) and androgen receptor knockout mice (Raskin et al., 2009) exhibit masculinized partner preference.

\section{ACTIVATIONAL EFFECTS OF STEROID HORMONES}

Sexual partner preferences are subject to activational effects of gonadal steroids in rodents. Intact females prefer males over females and intact males prefer estrous females over males (Hetta and Meyerson, 1978; Meyerson et al., 1980). In females, ovariectomy reduces sexual preference for a stimulus male which is restored by an injection of estradiol (Slob et al., 1987). In males, castration reduces sexual partner preference for an estrous female and either testosterone or estradiol restores it, but not dihydrotestosterone (DHT; Bakker et al., 1993). The ineffectiveness of DHT indicates that, like for other aspects of masculine sexual behavior, estrogenic metabolites produced by brain aromatase mediate the activational effects of testosterone. There is also evidence that sexual experience and adult hormone concentrations interact to form sexual partner preferences in both male and female rats (Slob et al., 1987; Woodson et al., 2002). More recently, TrianaDel Rio et al. (2011) reported that conditioned learning can elicit transitory same-sex partner preferences in cohabitating male, but not female rats, treated with the dopamine D2-type receptor agonist quinpirole (QNP). Thus, sexual partner preferences appear to be strongly influenced by an animals' steroid hormone environment which may be modified by other salient experiences and learning.

\section{ROLE OF OLFACTION}

Much social information is transported among rodents by the main and accessory olfactory systems, and the olfactory system is implicated in mate choice (Keller et al., 2006a,b). The main olfactory system has receptors in the nasal epithelium which synapse on the olfactory bulb with connections to the olfactory cortex in the temporal lobe as well as the amygdala and hypothalamus (Purves et al., 2008). The accessory olfactory system includes the vomeronasal organ and its connections. The vomeronasal organ, located in the oral cavity, is responsible for the detection of nonvolatile odors. In the absence of any cortical connections, the accessory olfactory system is responsible for the unconscious perception of odorants. Distinct receptors in the vomeronasal organ synapse on the accessory olfactory bulb with direct connections to the amygdala and hypothalamus (Purves et al., 2008). The accessory olfactory system is thought to process information about odorants from conspecifics and is important in the mediation of sexual, reproductive, and aggressive behaviors (Purves et al., 2008). Although much social information is relayed in the olfactory system, deafferentation of the olfactory bulb decreased the expression of sexual behavior but did not alter partner preference in sexually experienced male rats (Edwards et al., 1997). In contrast, a more severe bulbectomy in male hamsters decreased the preference for estrous females while sexual partner preference was unaffected following destruction of only the vomeronasal system (Ballard and Wood, 2007). These results suggest that the accessory olfactory system is not required for the normal expression of sexual partner preferences.

\section{ORGANIZATIONAL EFFECTS OF STEROID HORMONES}

Exposure to gonadal steroids during critical periods in development is important for the masculinization of adult sexual partner preferences in the rat. Henley et al. (2009) recently summarized the general principles concerning the organizational role of hormones on preference behavior. Prenatal exposure to the estrogenic metabolites of testosterone masculinizes sexual partner preferences resulting in a male-typical adult preference for an estrous female over a stimulus male (Matuszczyk et al., 1988; Brand and Slob, 1991). However, prenatal steroid exposure alone does not defeminize sexual partner preferences because males castrated 
neonatally and given estradiol and progesterone as adults prefer to spend time with sexually active males rather than estrous females (Matuszczyk et al., 1988). Like neonatally castrated rats, males treated postnatally with the aromatase inhibitor, ATD exhibit male-typical partner preference behavior, but also show femaletypical adult partner preferences for active males when treated with estradiol as adults (Bakker et al., 1993). Moreover, male rats castrated at birth or treated neonatally with ATD show a reduced preference for an estrous female when treated with testosterone in adulthood suggesting that prenatal steroid exposure only partially masculinizes partner preferences (Brand and Slob, 1991). Postnatal testosterone or estradiol exposure also has masculinizing and defeminizing effects on the display of adult partner preferences of female rats (de Jonge et al., 1988; Henley et al., 2009). Thus, complete masculinization of sexual partner preferences requires both pre- and post-natal exposure to estrogenic metabolites of testosterone, while postnatal exposure to estradiol leads to defeminization of adult rat partner preference.

\section{EFFECT OF PRENATAL STRESS}

Estrogenic metabolites of testosterone are required for the normal expression of male sexual behavior and are also necessary for neural organization which results in female-directed sexual partner preference in adulthood. The influence of prenatal stress on sexual partner preference provides further evidence of the organizational effect of gonadal steroids. Prenatal stress (either maternal nutrition or restraint stress) experienced during the last third of gestation affects testosterone synthesis in the prenatal male rat, suppresses preoptic aromatase activity (Weisz et al., 1982), and decreases expression of adult sexual behavior, especially copulatory behaviors (Rhees et al., 1999). Prenatal stress also prevents masculinization of female-directed partner preference behavior as measured by the time spent in proximity with an estrous female vs. a stimulus male (Meek et al., 2006; Wang et al., 2006; Popova et al., 2011). Stress negatively impacts the reproductive axis (Breen and Karsch, 2006) and since cortisol is lipophilic, endocrine stress events are likely to be transferred to the fetus. Elevated cortisol in obese ewes is mirrored by higher levels in their fetuses at 75 day of gestation (Ford et al., 2009), a time critical to the differentiation of the sheep brain.

\section{THE SEXUALLY DIMORPHIC PREOPTIC AREA}

The medial preoptic area (MPOA) acts as a nodal area for the integration of chemosensory information and the display of male sexual behaviors in all vertebrate species studied (Hull et al., 2002). Large lesions of the MPOA changed the partner preference of adult males so that in a choice test, they spend more time with an intact male than with an estrous female (Paredes et al., 1998). Similarly, ablation of the MPOA by chemical lesioning abolished the preference of intact male rats for soiled bedding from estrous females vs. intact males (Dhungel et al., 2011) supporting a role for MPOA in both olfactory preferences and male copulatory behavior. Other studies reported positive correlations between the volume of the sexually dimorphic preoptic nucleus (SDN-POA) and the animal's preference for a receptive female (Houtsmuller et al., 1994; Woodson et al., 2002). Prenatal stress affects expression of adult sexual behavior and reliably decreases the size of the
SDN-POA (Anderson et al., 1985). However, lesioning of the rat SDN-POA has not caused consistent behavioral deficits (Arendash and Gorski, 1983) and no experimental evidence exists that links this nucleus functionally to sexual partner preferences in rats.

\section{FERRETS}

Like rats, ferrets are also born in an altricial state with eye opening delayed until after postnatal day 23. Male ferrets are exposed to higher levels of testosterone than females at three distinct developmental periods: between embryonic days 28 and 38 of a 41-day gestation (Krohmer and Baum, 1989); acutely within $2 \mathrm{~h}$ after birth (Erskine et al., 1988); and over the first 3 weeks of life (Erskine and Baum, 1982). Both estrogens derived from testosterone and testosterone itself appears to be essential for sexual differentiation and partner preference development. Results of several experiments show that exposure of the male ferret to relatively high levels of circulating androgens during the last quarter of gestation and immediately after birth sensitize the developing neural mechanisms that control sexual behavior and partner preference to the lower levels of androgen that occur in males for several weeks after birth (Baum, 2003). The estrogens formed by the developing nervous system through aromatization of androgens are primarily responsible for this sensitization which allows the postnatal action of testosterone to complete the process of behavioral sexual differentiation.

\section{ACTIVATIONAL EFFECTS OF STEROID HORMONES}

Sexual partner preferences in ferrets are subject to activational effects of steroids. Male and female ferrets gonadectomized on postnatal day 35 and tested in later adulthood while receiving no hormone or testosterone displayed no significant preference when presented in a T-maze with a choice between an estrous female or stimulus male. When given estradiol benzoate, however, males preferred stimulus females whereas females preferred stimulus males (Stockman et al., 1985). The effectiveness of estradiol in femaledirected partner preference for male ferrets may be explained by the aromatization of testosterone to estradiol which is necessary for expression of masculine sexual behaviors (Baum et al., 1990a). The ineffectiveness of testosterone to activate heterosexual partner preferences in males, however, could be caused by interactions with the male stimulus animal leading to expression of aggression, which may predominate in this testing situation.

\section{THE ROLE OF OLFACTION}

Odor discrimination and sexual experience are important factors that bias sexual partner preferences of ferrets. Prior to sexual experience, testosterone propionate-treated males and estradiol benzoate-treated females prefer to approach odors from opposite sex ferrets, but clear preference to approach a goal box containing estrous female stimulus animal is evident only after males receive sexual experience (Kelliher and Baum, 2002). Heterosexual partner preference is eliminated in anosmic male and female ferrets even when the subjects were able to see, hear and interact physically with stimulus ferrets in a Y-maze (Kelliher and Baum, 2001). Additional experiments have established an obligatory role of olfactory cues in ferret heterosexual partner preference (Cloe et al., 2004; Woodley and Baum, 2004). Existing evidence suggests 
that a sex dimorphism in the detection of odorants by the main olfactory system as well as the central processing of pheromonal cues play central roles in mate recognition in ferrets (Baum, 2009).

\section{ORGANIZATIONAL EFFECTS OF STEROID HORMONES}

Developmental studies demonstrate that prolonged prenatal and early postnatal exposure to testosterone is necessary to establish male-typical partner preferences in ferrets (Stockman et al., 1985; Baum et al., 1990b). Females exposed to testosterone proprionate on embryonic day 27-30, at the time of birth, and again during postnatal days 5-20 chose the stimulus female in a T-maze test while receiving estradiol benzoate, a response identical to control males. Females exposed to testosterone prenatally or only after birth and from postnatal day 5-20 showed adult profiles of sexual partner preference that were intermediate between control males and females. The role that androgen metabolites play in the organization of sexual partner preferences in ferrets has not yet been addressed adequately.

\section{THE SEXUALLY DIMORPHIC PREOPTIC AREA}

Male ferrets possess a cluster of neurons in the posterior POA/AH that is absent in females and has been named the sexually dimorphic male nucleus (MN) of the POA/AH (Tobet et al., 1986b). The $\mathrm{MN}$ is organized by testosterone-derived estrogen acting during the last quarter of gestation (Tobet et al., 1986a). As opposed to the rat SDN-POA, the integrity of the male ferret $\mathrm{MN}$ is required for the male-typical preference to seek out and mate with an estrous female as opposed to a male stimulus animal (Cherry and Baum, 1990; Paredes and Baum, 1995; Kindon et al., 1996; Alekseyenko et al., 2007). Recently, it was demonstrated that bilateral electrolytic destruction of the MN caused male ferrets to exhibit a female-typical profile of preferences for male body odors which correlated with enhanced neural Fos-response to soiled bedding from other males (Alekseyenko et al., 2007). Taken together with earlier studies, hypothalamic processing of body odorants appears to underlie sex differences in partner preferences in ferrets.

\section{SHEEP}

Expression of normal ram sexual behavior requires both sexual interest and the execution of male-typical mounting behavior which is dependent on gonadal androgen production (D'Occhio and Brooks, 1980). Nearly 25\% of rams do not exhibit sexual interest in the presence of sexually receptive ewes. Although sexual behavior was estimated to be moderately heritable (Snowder et al., 2002), the incidence of sexually inactive rams did not differ in studies conducted in 1964 (Hulet et al., 1964) and 1991 (Fitzgerald and Perkins, 1991) at the US Sheep Experiment Station (Dubois, ID, USA). Since non-active rams are less reproductively successful, incidence of a highly heritable trait would be expected to decrease over time. The lack of a change, however, raises the possibility that the phenotypic expression of normal male sexual behavior does not appear to be entirely genotypically controlled.

\section{CHARACTERIZING SEXUAL PARTNER PREFERENCES OF RAMS}

Sexual behavior is assessed in rams by exposing rams to sexually receptive ewes in a serving capacity test in which numbers of courting and mounting behaviors expressed in $30 \mathrm{~min}$ are quantified. Sexual interest in other males is assessed in a sexual partner preference test. In a preference test, rams are exposed to both ewes in estrus as well as other rams. Female oriented rams (FOR) are quick to investigate estrous ewes and achieve 10 mounts and/or six ejaculations in a 30-min period (Perkins et al., 1992) and do not mount rams in sexual preference tests. Rams which exclusively court and mount other rams are considered male-oriented (MOR). Rams failing to show sexual interest in either estrous ewes or other rams, or achieve few mounts or ejaculations in the sexual performance test are classified as non-performing rams (NOR). Since Zenchak et al. (1981) first concluded that some rams prefer other rams as sexual partners, a number of additional reports have confirmed this observation (Perkins et al., 1995; Resko et al., 1996; Alexander et al., 1999; Pinckard et al., 2000). Notably, three independent studies estimated that MORs constitute $\sim 8 \%$ of a given ram population (Price et al., 1988; Perkins and Fitzgerald, 1992; Roselli et al., 2004b).

\section{THE ROLE OF OLFACTION}

Several hypotheses have been proposed to explain the expression of same-sex sexual preferences in rams. The most compelling lines of evidence implicate the involvement of sensory processing in the initial recognition of potential sexual partners which influences specific brain areas in the formulation of appropriate behavioral responses. Olfactory signals are important for facilitating reproduction in rams and are the major sensory modality used by rams to identify ewes in estrous (Maina and Katz, 1999). Intriguing evidence suggests that olfactory sensory processing differs between FORs and MORs. Perkins et al. (Perkins and Fitzgerald, 1992; Perkins et al., 1992) found that exposure of adult FORs to estrous ewes provokes an increase in LH and testosterone. MORs did not show this response to estrous ewes, but did exhibit an elevation in serum concentrations of testosterone when exposed to other rams. The hormone response in MORs, while paradoxical, suggests they respond differently than FORs when presented with similar sensory cues. Alexander et al. (1999) demonstrated that similar hormone responses could be evoked in FORs given fence line contact to estrous ewes in absence of direct sexual contact, but not to rams. In contrast, MORs (and NORs) did not show endocrine responses under those conditions. Interestingly, FORs exhibit more investigatory olfactory behaviors toward all stimulus animals suggesting that discrimination depends on adequate olfactory input. Following fence line exposure to ewes, FORs, but not MORs, have increased Fos-like activity in the bed nucleus of the stria terminalis and MPOA (Alexander et al., 2001) which are important components of the vomeronasal and olfactory pathways. Together, these results suggest that FORs detect and process sexually relevant information differently from MORs which may, in turn, contribute to differences in expression of sexual partner preferences.

\section{ORGANIZATIONAL EFFECTS OF STEROID HORMONES}

Evidence that the MPOA/AH participates in regulation of sexual partner preferences in rats and ferrets (see previous discussion) led to the search for a sexually dimorphic nucleus in the sheep. An ovine sexually dimorphic nucleus in the preoptic area (oSDNPOA) has been identified (Roselli et al., 2004a). The oSDN-POA is two to three times larger and contains more neurons in FORs than 
in MORs and ewes and is characterized by aromatase synthesizing neurons (Roselli et al., 2004a). Differences in the size of the oSDN among FORs, MORs, and ewes are not due to differences in adult exposure to testosterone since differences persist even after adult sheep are gonadectomized (Roselli et al., 2009). Sex differences in the size of the oSDN develop prior to birth under the organizational influences of testosterone (Roselli et al., 2007). These results suggest that differences in size of the oSDN between MORs and FORs arise from individual variations in prenatal androgen exposure or effects which may predispose adult rams to express sexual attraction to rams or ewes, respectively. Although this hypothesis cannot be tested directly, treatment of the pregnant ewe with an aromatase inhibitor did not disrupt masculinization of copulatory behavior and partner preferences and did not interfere with defeminization of the LH surge mechanism in adult rams (Roselli et al., 2006). Thus, the question of whether sexual partner preferences are programmed prenatally in rams remains unanswered. Correlation of oSDN size with sexual partner preference may function to bias the processing of sensory information (i.e., olfactory) relevant for mate choice. However, more research is needed to unravel the functional neuroanatomical relationships and the role, if any, of prenatal programming in the development and expression of adult sexual preferences in sheep.

\section{HUMANS}

In humans, gender is traditionally assigned by the presence of testes in the male and the absence of testes (implying the presence of ovaries) in females, whereas gender identity and sexual orientation are neurological effects. Gender identity is defined as whether a person perceives themselves as male or female regardless of anatomy and should be considered separately from gender behavior. Accordingly, a person with female gender identity may have masculine gender behavior. Orientation is defined by who we desire sexually, not necessarily whom we have sex with. There is overwhelming evidence in all species that prenatal hormone exposure is the most critical factor determining anatomical sex. Over the past 50 years, animal models have provided seminal information on how hormones regulate sex-typical brain anatomy and behavior. Those studies framed the nature of questions that are currently being posed regarding the influence of hormones on sexual identity and orientation. Although animal models have provided some insight into sex-typical orientation, they will never yield information regarding gender identity. Moreover, as orientation is also not simply binary, animal models are unlikely to resolve whether all etiologies underlying homosexuality are common - e.g., do masculine and effeminate gay men develop similarly?

\section{THEORIES BEHIND HUMAN PSYCHOSEXUAL DEVELOPMENT Optimal-gender policy}

John Money's hypothesis that the human brain is gender neutral at birth and evolves thereafter under the influence of experience/learning and hormones was advanced from the 1950s to the 1990s (Money and Ehrhardt, 1972). This policy shaped decision making for the medical, surgical, and psychological management of sexual development and especially "disorders" thereof. This policy was seriously undermined with the discovery that some 46,XY individuals with penile agenesis, penile ablation, or cloacalextrophy who were raised female, reassigned themselves with their genetic sex or experience gender dysphoria later in life (see MeyerBahlburg, 2005 for review). In contrast, no such individuals raised male reassigned their gender. It should be noted, however, that for some persons who have not undergone "complete" masculinization/defeminization neonatally [e.g., partial androgen insensitivity (PAIS), congenital adrenal hyperplasia (CAH) - see below] there is some support for the contention that gender identity, but not behavior, may be shaped by experience/learning (Wisniewski et al., 2008). However, how much of individual sex identification is determined by a need to conform to an established identity is uncertain since changing gender is not readily accepted in most societies.

\section{Genetics}

Studies on mammals (Carruth et al., 2002; Abel and Rissman, 2011) suggest that sex chromosome related genes contribute to sexual differentiation of the brain, but there is no evidence yet in humans to support a specific genetic component in the differentiation of gender identity. However, population studies and studies of identical twins support the hypothesis that at least some male and female homosexuality is a consequence of genetics (Bailey et al., 1991; Mustanski et al., 2005). Homosexuality runs in families (Bailey et al., 1991), and regions of the X chromosomes as well as chromosomes 7, 8, and 10 have been identified as sites of particular interest with respect to male homosexuality (Mustanski et al., 2005). However, candidate gene studies on the androgen receptor on Xq12 (Macke et al., 1993) or the enzyme aromatase on 15q21.2 (DuPree et al., 2004) have not demonstrated an association with male homosexuality. There is also evidence that birth order of boys may affect the potential of becoming gay with each additional older brother increasing the odds of becoming homosexual by approximately 33\% (Cantor et al., 2002). A pivotal study by Bogaert (2006) demonstrated that the fraternal birth order operates during prenatal life since the effect was observed even when the biological older brother was reared in a separate household. Furthermore, non-biological siblings (adopted or step-brothers) had no effect on men's sexual orientation (Bogaert, 2006). The most plausible, but not yet proven, explanation for this observation is that the mother develops an immune response that in some direct and/or indirect way, affects male fetal brain development during pregnancy. It is believed that this immune response is enhanced with each subsequent male pregnancy and increases the likelihood that some later born males will be sexually attracted to men as opposed to women (Bogaert and Skorska, 2011).

\section{Hormonal/Organizational}

Although still actively debated by the scientific community, there is growing support for the hypothesis that the prenatal hormone environment is a major determinant of gender behavior, gender identity, and sexual orientation. Although gonadal steroids are considered the major organizational effectors, evidence from mice suggests that MIH may also contribute to the sexual organization of the brain, at least in that species (Wang et al., 2009). Since receptors for other non-steroid reproductive hormones [gonadotropin releasing hormone $(\mathrm{GnRH}), \mathrm{LH}$, follicle stimulating hormone 
(FSH)] have been reported in the mammalian brain (Liu et al., 2007; Albertson et al., 2008), it is also possible that these hormones may be a component of endocrine-mediated neuronal differentiation. Although there is compelling evidence in other mammals that aromatization of testosterone to estrogen is critical for brain masculinization/defeminization, there is no evidence that this pathway affects gender or orientation in humans since men with null mutations affecting the expression of aromatase develop normal male-typical sexual orientation (Rochira et al., 2001).

During gestation, male and female fetuses have different endocrine profiles. A surge in testosterone commences after the differentiation of the bipotential gonads into testes in the male (Bakker et al., 1996; Baum, 2006; Scott et al., 2009; Bogaert and Skorska, 2011). The adrenal glands also produce androgens whose relative level can increase if there are perturbations in steroidogenic enzymes in this gland, such as in the case of CAH. Most commonly, an absence of hydroxylase activity inhibits cortisol synthesis in CAH individuals, and as a result of a lack of a negative feedback, the fetus is exposed to high levels of androgens (Shaw, 2010). The steroid profile of the mother may also get transferred to the fetus and thus maternal dysfunction of either the ovaries or adrenal glands are likely to be experienced by the developing conceptus. Other organs/tissues may also express enzymes capable of converting steroid precursors into androgens, such as the liver and adipose tissue which express $3 \beta$-hydroxysteroid dehydrogenase (HSD) and $17 \alpha$-HSD (Burger, 2002). Given the dramatic rise in obesity internationally and the strong association between obesity and polycystic ovarian syndrome (PCOS), characterized by hyperandrogenism (Ehrmann, 2005), the importance of adipose tissue in androgen synthesis should not be overlooked. Low levels of sex hormone binding globulin among obese or overweight women (Pugeat et al., 1991) may elevate the relative amount of free testosterone individuals are exposed to. However, one published study with a limited sample size reported a paradoxical decrease in umbilical cord blood androgens and estrogens of female fetuses born to PCOS women (Anderson et al., 2010). The placenta is also steroidogenically active and serves as a source of steroid hormones. Concentrations of steroid hormones in the amniotic fluid may better serve as an index of fetal exposure to steroids. The turnover of steroids is much slower in amniotic fluid than in blood (Lai et al., 1986) and acute episodes in the mother could result in chronic exposure to the fetus (Todaka et al., 2005).

The development of sexual anatomy in humans occurs in the first trimester before brain sexual differentiation in the second and third trimesters (Cohen-Kettenis, 2005). Both events are determined by testosterone, with external male sexual anatomy dependent on its conversion into DHT by $5 \alpha$-reductase-2. Although anatomical and neural differentiation occurs sequentially in most males, they are independent events (Cohen-Kettenis, 2005) as demonstrated in sheep (Roselli et al., 2011). It is, therefore, readily apparent that a person could develop male anatomy but retain a female brain. Big gaps in our knowledge base, in both human and animal studies, are "how much?" and "how long?" Sheep studies show that 30 vs. 60 days of androgen exposure produce different phenotypes, both anatomically and neurologically (Birch et al., 2003; Roberts et al., 2009). This evidence is, however, confounded by the gestational age when the fetus was exposed. Although the length of exposure differed, the timing of exposure also differed (30 vs. 60 day of gestation) which may influence the resulting phenotype. Further study is clearly needed to understand the implications of a shorter time period of androgen exposure.

In addition to the external sex organs, multiple organs, and tissues are also affected by exposure to steroids. It was suggested that the well-known effects of steroids on anogenital distance in mammalian studies, used as an index of androgen exposure, may also apply to humans (Swan, 2006). Although differentiation of the internal and external sexual organs is viewed collectively, evidence from humans suggests that we should consider differentiation of these structures separately. It was hypothesized in $46, \mathrm{XY}$ individuals that the degree of correlation between differentiation of external genitalia and gender identity is poor.

Hox genes are androgen sensitive (Daftary and Taylor, 2006) and are involved in digit growth. Numerous studies (see Breedlove, 2010 for review) have associated fetal androgen exposure with the length of the second finger relative to that of the ring finger (2D:4D ratio) and, although this ratio cannot be used as a quantitative assay, studies on persons who are completely androgen insensitive (CAIS) supports this hypothesis (Berenbaum et al., 2009). Several studies have related the 2D:4D ratio in homosexual women to greater androgen exposure (Grimbos et al., 2010).

Human males and females express specific behavioral differences which, by definition, are neurologically mediated (Hines, 2011). Accordingly, there are numerous neuroanatomical differences (see Bao and Swaab, 2010 for review) among men and women: from cortical thickness, which is greater in women (Luders et al., 2006), to the suprachiasmatic nucleus, which is more elongated in women (Swaab et al., 1985). Testosterone has even been implicated in cerebral lateralization (Grimshaw et al., 1995). Indeed, there may be few neurological structures that are not sexually dimorphic.

It is noteworthy that several of these nuclei differ according to sexual orientation or in disorders of sexual development. The suprachiasmatic nucleus in homosexual men is more similar in gross structure to that of a woman (Swaab and Hofman, 1990). The interstitial nucleus of the anterior hypothalamus 3 (INAH-3) is larger in males than in females (Garcia-Falgueras and Swaab, 2008) and is also smaller in homosexual than heterosexual men (LeVay, 1991). In addition, the volume and number of neurons present in the INAH-3 in 46,XY transsexual (i.e., male to female) people is similar to that in XX women (Garcia-Falgueras and Swaab, 2008). The isthmus of the corpus callosum is larger in right handed homosexual men than heterosexual men (Witelson et al., 2008). An MRI study to identify corpus callosum shape at the midsagittal plane found that callosal shape reflected gender identity rather than genetic sex (Yokota et al., 2005). Women and $46, \mathrm{XY}$ transsexual persons have a smaller central subregion of the bed nucleus of the stria terminalis (BNST) than men (Zhou et al., 1995), but the origin of this difference is controversial (Hines, 2011). Whether these neuroanatomically different sites actually play specific roles in gender identification and/or sexual orientation is not known. Indeed, they may simply reflect that, like the fingers, the brain has been exposed to a different endocrine milieu in utero. 


\section{DISORDERS OF SEXUAL DEVELOPMENT}

It can be argued that the terminology used in describing differences in sexual development induces a negative perception of these variations. Words such as "disorder," "mutation," "dysfunction" all have negative connotations at best and, at worst, suggests that these differences are fixable. It would be more helpful if we viewed such conditions as part of a natural continuum. However, these variations provide the strongest insight into the relative importance of the prenatal endocrine milieu on sexual differentiation.

\section{Swyer syndrome}

Probably the most compelling evidence that human neurological sexual differentiation is gonad dependent and independent of gene expression is provided by 46 , XY persons with pure gonadal dysgenesis, or Swyer syndrome (Wisniewski et al., 2008). These individuals are externally female with streak gonads and, if untreated with estrogens, do not experience puberty. All reported cases identify as heterosexual females and experience no gender dysphoria. Since there is no MIH, the Müllerian duct structures develop into a rudimentary uterus and vagina so that $46, \mathrm{XY}$ Swyer Syndrome women can maintain a pregnancy if treated hormonally.

\section{Androgen Insensitivity}

In CAIS, a 46,XY person is unable to respond to androgens although MIH prevents development of the Müllerian ducts. Such individuals are infertile. Persons with CAIS identify as heterosexual females and do not experience gender dysphoria. CAIS provides evidence that, in humans, MIH does not play a central role in sexual differentiation.

From a societal acceptance perspective, 46,XY women with Swyer syndrome or CAIS conform to the binary stereotype, i.e., male vs. female. In contrast, with 46,XY PAIS, the degree of anatomical and neurological differentiation depends on the extent of retained androgen sensitivity. Although attempts are made to raise persons as male or female, gender dysphoria is not uncommon (Wisniewski et al., 2008) and it is arguable that either category is appropriate.

\section{6,XY Congenital estrogen deficiency}

There are very few reported cases of $46, \mathrm{XY}$ estrogen deficiency caused by either estrogen insensitivity or aromatase deficiency (Rochira et al., 2001). Although there are some reproductive anomalies, all individuals identify as heterosexual males (Rochira et al., 2001). Although the numbers are limited, this evidence is persuasive that estrogen plays little role in human male-typical sexual differentiation.

\section{$5 \alpha$ Reductase-2 (SRD5A2) deficiency}

In $46, \mathrm{XY}$ men, differentiation of the external genitalia is dependent on DHT which is synthesized from testosterone by SRD5A2. In the absence of SRD5A2, the genitalia do not fully masculinize (Imperato-McGinley et al., 1979). Although this deficiency is rare in the general population, it is commonplace in several regions, being most prevalent in the Dominican Republic (1:90) and the Gaza strip (1:150). Depending on the extent of genital masculinization, individuals may be raised either male or female but, if the latter, incidence of gender reassignment is high (Imperato-McGinley et al., 1979; Cohen-Kettenis, 2005). In one study (Imperato-McGinley et al., 1979), of 18 persons unambiguously raised as girls, 17 changed to a male-gender identity, and 16 to a male-gender role during or after puberty. At puberty, the surge in testosterone accompanied by an assumed increase in $5 \alpha$ reductase- 1 synthesis (Wilson, 2001), results in increased virilization.

\section{Transsexual}

If there is masculinization/defeminization of the genitalia, but not the brain, it would be hypothesized that a 46,XY transgendered person develops. Studies by Savic and Arver (2011) support this hypothesis, but the number of individuals studied is very small. In some societies, most notably Independent Samoa, 46, XY transgendered persons indentify as a third gender, fa'fafine, which is feminine and there is no societal stigmatization associated with this gender. Fa'fafine are indentified at a very early age and seminal studies by Vasey et al. (2011) suggest that their psychosocial development is similar to girls, supporting the hypothesis that their brains have not undergone masculinization/defeminization. It is of note that fraternal birth order has been associated with the probability of a fa'fafine being born (VanderLaan and Vasey, 2011).

\section{Congenital adrenal hyperplasia (CAH)}

The most common form of CAH is $21 \alpha$-hydroxylase deficiency which reduces the synthesis of cortisol and aldosterone. As a result there is an increased synthesis of androgens by the adrenal gland. The range of genital masculinization is variable and, although there is an assumption that this is a reflection of neural masculinization, and hence gender assignment, this may not be accurate. Since Wolffian duct virilization is testosterone dependent, independent of its conversion to DHT, it may be a better index of masculinization/defeminization of the brain than external genitalia (Randall, 1994; Ostrer, 2000; Hannema and Hughes, 2007). Although female gender assignment predominates in $\mathrm{CAH}$ and is retained, there are elevated instances of strong gender dysphoria (Dessens et al., 2005) arguing that in some persons an androgen duration and/or concentration threshold has been surpassed. It is noteworthy that there is a much higher incidence of tomboyish behavior as children (Ehrhardt and Meyer-Bahlburg, 1981) and homosexuality as adults and the 2D:4D finger ratio is masculinized (Brown et al., 2002; Okten et al., 2002).

\section{Diethylstilbestrol and other xeno- and phyto-steroids}

Diethylstilbestrol, a synthetic estrogen, was first synthesized in 1938 but, like several other xeno- and phyto-estrogens, it has affinity for the androgen receptor (Wang et al., 2010). Between 1940 and 1970, DES was used as a gestation facilitator and approximately 2 million US babies were exposed in utero although the duration and dose of DES were variable. Interestingly, there is a higher incidence of homosexuality in women exposed to DES as fetuses (Ehrhardt et al., 1985). Anecdotal evidence (Swaab, 2007) also suggested a higher incidence of DES exposure in 46,XY transgendered persons. There are numerous reports of an association between xenoand phyto-estrogens and impaired sexual differentiation although most have focused on the effects on sexual anatomy and, by inference, the brain. For example, exposure to high levels of genistein or fungicides, which may act as xenosteroids, are associated with 
a higher incidence of hypospadias in men. Methoxyacetic acid, the primary active metabolite of the industrial chemical ethylene glycol monomethyl ether, disrupts spermatogenesis, and causes testicular atrophy was shown to affect androgen sensitive HOX genes (Bagchi et al., 2011).

\section{CONCLUSION}

There is compelling evidence that perinatal exposure to gonadal steroids is one of the biological factors that strongly influences the development of sexual partner preferences in animals and sexual orientation in humans. The specific effects of testosterone and its aromatase-derived estrogenic metabolites in these differentiation processes are clearly species dependent and range from being almost exclusively dependent on estrogen in the rat to androgen dependent in humans. Many tissues are profoundly affected by these steroids in development. Sexual differentiation of the genitals occurs before sexual differentiation of the brain and is subject to varying and independent degrees of masculinization. In the brain, specific steroid-dependent nuclei have been identified that are dimorphic both with regard to sex and sexual orientation/partner preference. However, our knowledge of the roles these nuclei play in manifesting sexual behaviors and partner preferences remains

\section{REFERENCES}

Abel, J., and Rissman, E. (2011). Location, location, location: genetic regulation of neural sex differences. Rev. Endocr. Metab. Disord. 1-11.

Adkins-Regan, E., Thompson, V. M. R., and Yang, S. (1997). Organizational actions of sex hormones on sexual partner preference. Brain Res. Bull. 44, 497-502.

Albertson, A. J., Navratil, A., Mignot, M., Dufourny, L., Cherrington, B., and Skinner, D. C. (2008). Immunoreactive GnRH type I receptors in the mouse and sheep brain. J. Chem. Neuroanat. 35, 326-333.

Alekseyenko, O. V., Waters, P., Zhou, H., and Baum, M. J. (2007). Bilateral damage to the sexually dimorphic medial preoptic area/anterior hypothalamus of male ferrets causes a female-typical preference for and a hypothalamic Fos response to male body odors. Physiol. Behav. 90, 438-449.

Alexander, B. M., Rose, J. D., Stellflug, J. N., Fitzgerald, J. A., and Moss, G. E. (2001). Fos-like immunoreactivity in brain regions of domestic rams following exposure to rams or ewes. Physiol. Behav. 73, 75-80.

Alexander, B. M., Stellflug, J. N., Rose, J. D., Fitzgerald, J. A., and Moss, G. E. (1999). Behavior and endocrine changes in highperforming, low-performing, and male-oriented domestic rams following exposure to rams and ewes in estrus when copulation is precluded. J. Anim. Sci. 77, 1869-1874.
Anderson, D. K., Rhees, R. W., and Fleming, D. E. (1985). Effects of prenatal stress on differentiation of the sexually dimorphic nucleus of the preoptic area (SDN-POA) of the rat brain. Brain Res. 332, 113-118.

Anderson, H., Fogel, N., Grebe, S. K., Singh, R. J., Taylor, R. L., and Dunaif, A. (2010). Infants of women with polycystic ovary syndrome have lower cord blood androstenedione and estradiol levels. J. Clin. Endocrinol. Metab. 95, 2180-2186.

Arendash, G. W., and Gorski, R. A. the sexually dimorphic nucleus of the preoptic area or other medial preoptic regions on the sexual behavior of male rats. Brain Res. Bull. 10, 147-154.

Bagchi, G., Zhang, Y., Stanley, K. A., and Waxman, D. J. (2011). Complex modulation of androgen responsive gene expression by methoxyacetic acid. Reprod. Biol. Endocrinol. 9, 42.

Bagemihl, B. (1999). Biological Exuberance: Animal Homosexuality and Natural Diversity. New York: St. Martin's Press.

Bailey, J. M., Willerman, L., and Parks, C. (1991). A test of the maternal stress theory of human male homosexuality. Arch. Sex. Behav. 20, 277-293.

Bakker, J., Brand, T., Van Ophemert, J., regulation of adult partner preference behavior in neonatally ATDtreated male rats. Behav. Neurosci. 107, 480-487. (1983). Effects of discrete lesions of and Slob, A. K. (1993). Hormonal

very meager. Although rodents are tractable models, especially because dimorphisms develop postnatally, studies are hampered by size which limits our ability to precisely manipulate target nuclei in vivo. Sheep and ferrets, by contrast, have larger brains making such targeted manipulations feasible but require specialized surgical techniques to perform in utero experiments. Moreover, the seemingly essential requirement that steroid exposure occurs for long periods makes such studies even more challenging. Indeed, the precise stage of development and steroid dose required remain unresolved. These and other questions remain to be answered and in a broader context will undoubtedly expand our understanding of the hormonal control of sexual differentiation.

Summary Sentence: This manuscript reviews the major findings which support the hypothesis that perinatal exposure to gonadal steroids is responsible for the development of sexual partner preferences in animals and explores how this information has helped to frame our understanding of human sexual orientation and gender identity.

\section{ACKNOWLEDGMENTS}

This work was supported by NIH R01 RR014270 (Charles E. Roselli).

Bakker, J., Van Ophemert, J., and Slob, A. K. (1996). Sexual differentiation of odor and partner preference in the rat. Physiol. Behav. 60, 489-494.

Ballard, C. L., and Wood, R. I. (2007). Partner preference in male hamsters: steroids, sexual experience and chemosensory cues. Physiol. Behav. 91, 1-8.

Bao, A.-M., and Swaab, D. F. (2010). Sex differences in the brain, behavior, and neuropsychiatric disorders. Neuroscientist 16, 550-565.

Baum, M. J. (2003). Activational and organizational effects of estradiol on male behavioral neuroendocrine function. Scand. J. Psychol. 44, 213-220.

Baum, M. J. (2006). Mammalian animal models of psychosexual differentiation: when is "translation" to the human situation possible? Horm. Behav. 50, 579-588.

Baum, M. J. (2009). Sexual differentiation of pheromone processing: links to male-typical mating behavior and partner preference. Horm. Behav. 55, 579-588.

Baum, M. J., Carroll, R. S., Cherrv, J. A., and Tobet, S. A. (1990a). Steroidal control of behavioural, neuroendocrine and brain sexual differentiation: studies in a carnivore, the ferret. J. Neuroendocrinol. 2, 401-418.

Baum, M. J., Erskine, M. S., Kornberg, E., and Weaver, C. E. (1990b). Prenatal and neonatal testosterone exposure interact to affect differentiation of sexual behavior and partner preference in female ferrets. Behav. Neurosci. 104, 183-198.

Berenbaum, S. A., Bryk, K. K., Nowak, N., Quigley, C. A., and Moffat, S. (2009). Fingers as a marker of prenatal androgen exposure. Endocrinology 150, 5119-5124.

Birch, R. A., Padmanabhan, V., Foster, D. L., Unsworth, W. P., and Robinson, J. E. (2003). Prenatal programming of reproductive neuroendocrine function: fetal androgen exposure produces progressive disruption of reproductive cycles in sheep. Endocrinology 144, 1426-1434.

Bogaert, A. F. (2006). Biological versus nonbiological older brothers and men's sexual orientation. Proc. Natal. Acad. Sci. U.S.A. 103, 10771-10774.

Bogaert, A. F., and Skorska, M. (2011). Sexual orientation, fraternal birth order, and the maternal immune hypothesis: a review. Front. Neuroendocrinol. 32:247-254. doi:10.1016/j.yfrne.2011.02.004

Brand, T., and Slob, A. K. (1991). Neonatal organization of adult partner preference behavior in male rats. Physiol. Behav. 49, 107-111.

Breedlove, S. M. (2010). Minireview: organizational hypothesis: instances of the fingerpost. Endocrinology 151, 4116-4122.

Breen, K. M., and Karsch, F. J. (2006) New insights regarding glucocorticoids, stress and gonadotropin suppression. Front. Neuroendocrinol. 27:233-245. doi: 10.1016/j.yfrne. 2006.03.335 
Brown, W. M., Finn, C. J., Cooke, B. M., and Breedlove, S. M. (2002). Differences in finger length ratios between self-Identified "butch" and "femme" lesbians. Arch. Sex. Behav. 31, 123-127.

Burger, H. G. (2002). Androgen production in women. Fertil. Steril. 77(Suppl. 4), S3-S5.

Cantor, J. M., Blanchard, R., Paterson, A. D., and Bogaert, A. F. (2002). How many gay men owe their sexual orientation to fraternal birth order? Arch. Sex. Behav. 31, 63-71.

Carruth, L. L., Reisert, I., and Arnold, A. P. (2002). Sex chromosome genes directly affect brain sexual differentiation. Nat. Neurosci. 5, 933-934.

Cherry, J. A., and Baum, M. J. (1990). Effects of lesions of a sexually dimorphic nucleus in the preoptic/anterior hypothalamic area on the expression of androgen- and estrogendependent sexual behaviors in male ferrets. Brain Res. 522, 191-203.

Cloe, A. L., Woodley, S. K., Waters, P., Zhou, H., and Baum, M. J. (2004). Contribution of anal scent gland and urinary odorants to mate recognition in the ferret. Physiol. Behav. 82, 871-875.

Cohen-Kettenis, P. T. (2005). Gender change in 46,XY persons with 5alpha-reductase-2 deficiency and 17beta-hydroxysteroid dehydrogenase-3 deficiency. Arch. Sex. Behav. 34, 399-410.

Daftary, G. S., and Taylor, H. S. (2006). Endocrine regulation of HOX genes. Endocr. Rev. 27, 331-355.

de Jonge, F. H., Muntjewerff, J. W., Louwerse, A. L., and Van De Poll, N. E. (1988). Sexual behavior and sexual orientation of the female rat after hormonal treatment during various stages of development. Horm. Behav. 22, 100-115.

Dessens, A. B., Slijper, F. M., and Drop, S. L. (2005). Gender dysphoria and gender change in chromosomal females with congenital adrenal hyperplasia. Arch. Sex. Behav. 34, 389-397.

Dhungel, S., Urakawa, S., Kondo, Y., and Sakuma, Y. (2011). Olfactory preference in the male rat depends on multiple chemosensory inputs converging on the preoptic area. Horm. Behav. 59, 193-199.

D'Occhio, M. J., and Brooks, D. E. (1980). Effects of androgenic and oestrogenic hormones on mating behaviour in rams castrated before or after puberty. J. Endocrinol. 86, 403-411.

DuPree, M. G., Mustanski, B. S., Bocklandt, S., Nievergelt, C., and Hamer, D. H. (2004). A Candidate gene study of CYP19 (Aromatase) and male sexual orientation. Behav. Genet. 34, 243-250.

Edwards, D. A., Walter, B. E. N., and Liang, P. (1997). Hypothalamic and olfactory control of sexual behavior and partner preference in male rats. Physiol. Behav. 60, 1347-1354.

Ehrhardt, A. A., and Meyer-Bahlburg, H. F. (1981). Effects of prenatal sex hormones on gender-related behavior. Science 211, 1312-1318.

Ehrhardt, A. A., Meyer-Bahlburg, H. F., Rosen, L. R., Feldman, J. F., Veridiano, N. P., Zimmerman, I., and McEwen, B. S. (1985). Sexual orientation after prenatal exposure to exogenous estrogen. Arch. Sex. Behav. 14, 57-77.

Ehrmann, D. A. (2005). Polycystic ovary syndrome. N. Engl. J. Med. 352, 1223-1236.

Erskine, M. S., and Baum, M. J. (1982). Plasma concentrations of testosterone and dihydrotestosterone during perinatal development in male and female ferrets. Endocrinology 111, 767-772.

Erskine, M. S., Tobet, S. A., and Baum, M. J. (1988). Effect of birth on plasma testosterone, brain aromatase activity, and hypothalamic estradiol in male and female ferrets. Endocrinology 122, 524-530.

Fitzgerald, J. A., and Perkins, A. (1991). Ram sexual performance: a relationship with dam productivity. SID Sheep Res. J. 7, 7-10.

Ford, S. P., Zhang, L., Zhu, M., Miller, M. M., Smith, D. T., Hess, B. W., Moss, G. E., Nathanielsz, P. W., and Nijland, M. J. (2009). Maternal obesity accelerates fetal pancreatic beta-cell but not alpha-cell development in sheep: prenatal consequences. Am. J. Physiol. Regul. Integr. Comp. Physiol. 297, R835-R843.

Garcia-Falgueras, A., and Swaab, D. F. (2008). A sex difference in the hypothalamic uncinate nucleus: relationship to gender identity. Brain 131, 3132-3146.

Goy, R. W., and McEwen, B. S. (1980). Sexual Differentiation of the Brain. Cambridge: MIT Press.

Grimbos, T., Dawood, K., Burriss, R. P., Zucker, K. J., and Puts, D. A. (2010). Sexual orientation and the second to fourth finger length ratio: a metaanalysis in men and women. Behav. Neurosci. 124, 278-287.

Grimshaw, G. M., Bryden, M. P., and Finegan, J. K. (1995). Relations between prenatal testosterone and cerebral lateralization in children. Neuropsychology 9, 68-79.

Hamson, D. K., Csupity, A. S., Ali, F. M., and Watson, N. V. (2009). Partner preference and mount latency are masculinized in androgen insensitive rats. Physiol. Behav. 98 25-30.

Hannema, S. E., and Hughes, I. A. (2007). Regulation of Wolffian duct development. Horm. Res. Paediatr. 67, 142-151.

Henley, C. L., Nunez, A. A., and Clemens, L. G. (2009). Estrogen treatment during development alters adult partner preference and reproductive behavior in female laboratory rats. Horm. Behav. 55, 68-75.

Henley, C. L., Nunez, A. A., and Clemens, L. G. (2011). Hormones of choice: the neuroendocrinology of partner preference in animals. Front. Neuroendocrinol. 32:146-154. doi:10.1016/j.yfrne.2011.02.010

Hetta, J., and Meyerson, B. J. (1978). Sexual motivation in the male rat: a methodological study of sexspecific orientation and the effects of gonadal steroids. Acta Physiol. Scand. Suppl. 453, 5-27.

Hines, M. (2011). Gender development and the human brain. Annu. Rev. Neurosci. 34, 69-88.

Houtsmuller, E. J., Brand, T., de Jonge, F. H., Joosten, R. N. J. M. A., van de Poll, N. E., and Slob, A. K. (1994). SDN-POA volume, sexual behavior, and partner preference of male rats affected by perinatal treatment with ATD. Physiol. Behav. 56, 535-541.

Hulet, C. V., Blackwell, R. L., and Ercanbrack, S. K. (1964). Observations on sexually inhibited rams. J. Anim. Sci. 23, 1095-1097.

Hull, E. M., Meisel, R. L., and Sachs, B. D. (2002). "Male sexual behavior" in Hormones, Brain, and Behavior, eds D. W. Pfaff, A. P. Arnold, A. M. Etgen, S. E. Fahrbach, and R. T. Rubin (San Diego: Academic Press), 3-137.

Imperato-McGinley, J., Peterson, R. E., Gautier, T., and Sturla, E. (1979). Male pseudohermaphroditism secondary to 5 alphareductase deficiency-a model for the role of androgens in both the development of the male phenotype and the evolution of a male gender identity. J. Steroid Biochem. 11, 637-645.

Keller, M., Douhard, Q., Baum, M. J., and Bakker, J. (2006a). Destruction of the main olfactory epithelium reduces female sexual behavior and olfactory investigation in female mice. Chem. Senses 31, 315-323.

Keller, M., Pierman, S., Douhard, Q., Baum, M. J., and Bakker, J. (2006b). The vomeronasal organ is required for the expression of lordosis behaviour, but not sex discrimination in female mice. Eur. J. Neurosci. 23, 521-530.

Kelliher, K., and Baum, M. (2002). Effect of sex steroids and coital experience on ferrets' preference for the smell, sight and sound of conspecifics. Physiol. Behav. 76, 1-7.

Kelliher, K. R., and Baum, M. J. (2001). Nares occlusion eliminates heterosexual partner selection without disrupting coitus in ferrets of both sexes. J. Neurosci. 21, 5832-5840.

Kindon, H. A., Baum, M. J., and Paredes, R. J. (1996). Medial preoptic/anterior hypothalamic lesions induce a female-typical profile of sexual partner preference in male ferrets. Horm. Behav. 30, 514-527.

Krohmer, R. W., and Baum, M. J. (1989). Effect of sex, intrauterine position and androgen manipulation on the development of brain aromatase activity in fetal ferrets. $J$. Neuroendocrinol. 1, 265-271.

Lai, P. C., Mears, G. J., and Lorscheider, F. L. (1986). Fetal-maternal transfer of [H3]-6 beta-hydroxycortisol in the pregnant ewe. Horm. Metab. Res. 18, 526-529.

LeVay, S. (1991). A difference in hypothalamic structure between heterosexual and homosexual men. Science 253, 1034-1037.

Liu, T., Wimalasena, J., Bowen, R. L., and Atwood, C. S. (2007). Luteinizing hormone receptor mediates neuronal pregnenolone production via up-regulation of steroidogenic acute regulatory protein expression. J. Neurochem. 100, 1329-1339.

Luders, E., Narr, K. L., Thompson, P. M., Rex, D. E., Jancke, L., and Toga, A. W. (2006). Hemispheric asymmetries in cortical thickness. Cereb. Cortex 16, 1232-1238.

Macke, J. P., Hu, N., Hu, S., Bailey, M., King, V. L., Brown, T., Hamer, D., and Nathans, J. (1993). Sequence variation in the androgen receptor gene is not a common determinant of male sexual orientation. Am. J. Hum. Genet. 53, 844-852.

Maina, D., and Katz, L. S. (1999). Scent of a Ewe: Transmission of a social cue by conspecifics affects sexual performance in male sheep. Biol. Reprod. 60, 1373-1377.

Matuszczyk, J. V., Fernandez-Guasti, A., and Larsson, K. (1988). Sexual orientation, proceptivity, and receptivity in the male rat as a function of neonatal hormonal manipulation. Horm. Behav. 22, 362-378.

Meek, L. R., Schulz, K. M., and Keith, C. A. (2006). Effects of prenatal stress on sexual partner preference in mice. Physiol. Behav. 89, 133-138.

Meyer-Bahlburg, H. F. (2005). Gender identity outcome in female-raised 46,XY persons with penile agenesis, cloacal exstrophy of the bladder, or penile ablation. Arch. Sex. Behav. 34, 423-438. 
Meyerson, B. J., Eliasson, M., and Hetta, J. (1980). "Sex-specific orientation in female and male rats: development and effects of early endocrine manipulation," in Development of Responsiveness to Steroid Hormones: Advances in the Biosciences, ed. M. Kaye (Oxford: Pergamon Press), 451-460.

Money, J., and Ehrhardt, A. A. (1972). Man and Woman, Boy and Girl: Differentiation and Dimorphism of Gender Identity from Conception to Maturity. Baltimore, MD: Johns Hopkins University Press.

Mustanski, B. S., Dupree, M. G., Nievergelt, C. M., Bocklandt, S., Schork, N. J., and Hamer, D. H. (2005). A genomewide scan of male sexual orientation. Hum. Genet. 116, 272-278.

Okten, A., Kalyoncu, M., and Yaris, N. (2002). The ratio of second- and fourth-digit lengths and congenital adrenal hyperplasia due to 21hydroxylase deficiency. Early Hum. Dev. 70, 47-54.

Ostrer, H. (2000). Sexual differentiation. Semin. Reprod. Med. 18, 41-49.

Paredes, R. G., and Baum, M. J. (1995). Altered sexual partner preference in male ferrets given excitotoxic lesions of the preoptic area/anterior hypothalamus. J. Neurosci. 15, 6619-6630.

Paredes, R. G., Tzschentke, T., and Nakach, N. (1998). Lesions of the medial preoptic area/anterior hypothalamus (MPOA/AH) modify partner preference in male rats. Brain Res. 813, 1-8.

Patisaul, H. B., and Polston, E. K. (2008). Influence of endocrine active compounds on the developing rodent brain. Brain Res. Rev. 57, 352-362.

Perkins, A., and Fitzgerald, J. A. (1992). Luteinizing hormone, testosterone, and behavioral response of male-oriented rams to estrous ewes and rams. J. Anim. Sci. 70, 1787-1794.

Perkins, A., Fitzgerald, J. A., and Moss, G. E. (1995). A comparison of LH secretion and brain estradiol receptors in heterosexual and homosexual rams and female sheep. Horm. Behav. 29, 31-41.

Perkins, A., Fitzgerald, J. A., and Price, E. O. (1992). Luteinizing hormone and testosterone response of sexually active and inactive rams. J. Anim. Sci. 70, 2086-2093.

Phoenix, C. H., Goy, R. W., Gerall, A. A., and Young, W. C. (1959). Organizing action of prenatally administered testosterone propionate on the tissues mediating mating behavior in the female guinea pig. Endocrinology $65,369-382$.
Pinckard, K. L., Stellflug, J., and Stormshak, F. (2000). Influence of castration and estrogen replacement on sexual behavior of femaleoriented, male-oriented, and asexual rams. J. Anim. Sci. 78, 1947-1953.

Popova, N. K., Morozova, M. V., and Amstislavskaya, T. G. (2011). Prenatal stress and ethanol exposure produces inversion of sexual partner preference in mice. Neurosci. Lett. 489, 48-52.

Price, E. O., Katz, L. S., Wallach, S. J. R., and Zenchak, J. J. (1988). The relationship of male-male mounting to the sexual preferences of young rams. Appl. Anim. Behav. Sci. 21, 347-355.

Pugeat, M., Crave, J. C., Elmidani, M., Nicolas, M. H., Garoscio-Cholet, M., Lejeune, H., Déchaud, H., and Tourniaire, J. (1991). Pathophysiology of sex hormone binding globulin (SHBG): relation to insulin. $J$. Steroid Biochem. 40, 841-849.

Purves, D., Augustine, G. J., Fitzpatrick, D., Hall, W. C., Lamantia, A. S., Mcnamara, J. O., and White, L. E. (2008). Neuroscience. Sunderland, MA: Sinauer Associates, Inc.

Randall, V. A. (1994). Role of 5 alphareductase in health and disease. Baillieres Clin Endocrinol. Metab. 8, 405-431.

Raskin, K., De Gendt, K., Duittoz, A., Liere, P., Verhoeven, G., Tronche, F., and Mhaouty-Kodja, S. (2009). Conditional inactivation of androgen receptor gene in the nervous system: effects on male behavioral and neuroendocrine responses. J. Neurosci. 29, 4461-4470.

Resko, J. A., Perkins, A., Roselli, C. E., Fitzgerald, J. A., Choate, J. V., and Stormshak, F. (1996). Endocrine correlates of partner preference behavior in rams. Biol. Reprod. 55, 120-126.

Rhees, R. W., Al-Saleh, H. N., Kinghorn, E. W., Fleming, D. E., and Lephart, E. D. (1999). Relationship between sexual behavior and sexually dimorphic structures in the anterior hypothalamus in control and prenatally stressed male rats. Brain Res. Bull. 50, 193-199.

Roberts, E. K., Flak, J. N., Ye, W., Padmanabhan, V., and Lee, T. M. (2009). Juvenile rank can predict male-typical adult mating behavior in female sheep treated prenatally with testosterone. Biol. Reprod. 80, 737-742.

Rochira, V., Balestrieri, A., Madeo, B., Baraldi, E., Faustini-Fustini, M., Granata, A. R., and Carani, C. (2001). Congenital estrogen deficiency: in search of the estrogen role in human male reproduction. Mol. Cell. Endocrinol. 178, 107-115.
Roselli, C., Schrunk, J., Stadelman, H., Resko, J., and Stormshak, F. (2006). The effect of aromatase inhibition on the sexual differentiation of the sheep brain. Endocrine 29, 501-511.

Roselli, C. E., Estill, C. T., Stadelman, H. L., Meaker, M., and Stormshak, F. (2011). Separate critical periods exist for testosterone-induced differentiation of the brain and genitals in sheep. Endocrinology 152, 2409-2415.

Roselli, C. E., Estill, C. T., Stadelman, H. L., and Stormshak, F. (2009). The volume of the ovine sexually dimorphic nucleus of the preoptic area is independent of adult testosterone concentrations. Brain Res. 1249, 113-117.

Roselli, C. E., Larkin, K., Resko, J. A., Stellflug, J. N., and Stormshak, F. (2004a). The volume of a sexually dimorphic nucleus in the ovine medial preoptic area/anterior hypothalamus varies with sexual partner preference. Endocrinology 145, 478-483.

Roselli, C. E., Larkin, K., Schrunk, J. M., and Stormshak, F. (2004b). Sexual partner preference, hypothalamic morphology and aromatase in rams. Physiol. Behav. 83, 233-245.

Roselli, C. E., Stadelman, H., Reeve, R., Bishop, C. V., and Stormshak, F. (2007). The ovine sexually dimorphic nucleus of the medial preoptic area is organized prenatally by testosterone. Endocrinology 148 , 4450-4457.

Ryan, B. C., and Vandenbergh, J. G. (2002). Intrauterine position effects. Neurosci. Biobehav. Rev. 26, 665-678.

Savic, I., and Arver, S. (2011). Sex dimorphism of the brain in male-tofemale transsexuals. Cereb. Cortex. doi: 10.1093/cercor/bhr032. [Epub ahead of print].

Scott, H. M., Mason, J. I., and Sharpe, R. M. (2009). Steroidogenesis in the fetal testis and its susceptibility to disruption by exogenous compounds. Endocr. Rev. 30, 883-925.

Shaw, A. M. (2010). 21-Hydroxylase deficiency congenital adrenal hyperplasia. Neonatal Netw. 29, 191-196.

Slob, A. K., de Klerk, L. W., and Brand, T. (1987). Homosexual and heterosexual partner preference in ovariectomized female rats: effects of testosterone, estradiol and mating experience. Physiol. Behav. 41, 571-576.

Snowder, G. D., Stellflug, J. N., and Van Vleck, L. D. (2002). Heritability and repeatability of sexual performance scores of rams. J. Anim. Sci. 80, 1508-1511.

Stockman, E. R., Callaghan, R. S., and Baum, M. J. (1985). Effects of neonatal castration and testosterone treatment on sexual partner preference in the ferret. Physiol. Behav. 34, 409-414.

Swaab, D. F. (2007). Sexual differentiation of the brain and behavior. Best Pract. Res. Clin. Endocrinol. Metab. 21, 431-444.

Swaab, D. F., Fliers, E., and Partiman, T. S. (1985). The suprachiasmatic nucleus of the human brain in relation to sex, age and senile dementia. Brain Res. 342, 37-44.

Swaab, D. F., and Hofman, M. A (1990). An enlarged suprachiasmatic nucleus in homosexual men. Brain Res. 537, 141-148.

Swan, S. H. (2006). Prenatal phthalate exposure and anogenital distance in male infants. Environ. Health Perspect. 114, A88-A99.

Tobet, S. A., Zahniser, D. J., and Baum, M. J. (1986a). Differentiation in male ferrets of a sexually dimorphic nucleus of the preoptic/anterior hypothalamic area requires prenatal estrogen. Neuroendocrinology 44, 299-308.

Tobet, S. A., Zahniser, D. J., and Baum, M. J. (1986b). Sexual dimorphism in the preoptic/anterior hypothalamic area of ferrets: effects of adult exposure to sex steroids. Brain Res. 364 , 249-257.

Todaka, E., Sakurai, K., Fukata, H., Miyagawa, H., Uzuki, M., Omori, M., Osada, H., Ikezuki, Y., Tsutsumi, O., Iguchi, T., and Mori, C. (2005). Fetal exposure to phytoestrogens - the difference in phytoestrogen status between mother and fetus. Environ. Res. 99, 195-203.

Triana-Del Rio, R., MonteroDomínguez, F., Cibrian-Llanderal, T., Tecamachaltzi-Silvaran, M. B., Garcia, L. I., Manzo, J., Hernandez, M. E., and Coria-Avila, G. A. (2011). Same-sex cohabitation under the effects of quinpirole induces a conditioned sociosexual partner preference in males, but not in female rats. Pharmacol. Biochem. Behav. 99, 604-613.

VanderLaan, D. P., and Vasey, P. L. (2011). Male sexual orientation in independent samoa: evidence for fraternal birth order and maternal fecundity effects. Arch. Sex. Behav. 40, 495-503.

Vasey, P. L. (2002). Same-sex sexual partner preference in hormonally and neurologically unmanipulated animals. Annu. Rev. Sex Res. 13, 141-179.

Vasey, P. L., Vanderlaan, D. P., Gothreau, L. M., and Bartlett, N. H. (2011). Traits of separation anxiety in childhood: a retrospective study of Samoan men, women, and fa' afafine. Arch. Sex. Behav. 40, 511-517. 
Wang, C. T., Shui, H. A., Huang, R. L., Tai, M. Y., Peng, M. T., and Tsai, Y. F. (2006). Sexual motivation is demasculinized, but not feminized, in prenatally stressed male rats. $\mathrm{Neu}$ roscience 138, 357-364.

Wang, H., Li, J., Gao, Y., Xu, Y., Pan, Y., Tsuji, I., Sun, Z. J., and Li, X. M. (2010). Xeno-oestrogens and phytooestrogens are alternative ligands for the androgen receptor. Asian J. Androl. 12, 535-547.

Wang, P. Y., Protheroe, A., Clarkson, A. N., Imhoff, F., Koishi, K., and Mclennan, I. S. (2009). Mullerian inhibiting substance contributes to sex-linked biases in the brain and behavior. Proc. Natl. Acad. Sci. U.S.A. 106, 7203-7208.

Weisz, J., Brown, B. L., and Ward, I. L. (1982). Maternal stress decreases steroid aromatase activity in brains of male and female rat fetuses. $\mathrm{Neu}$ roendocrinology 35, 374-379.

Wilson, J. D. (2001). Androgens, androgen receptors, and male gender role behavior. Horm. Behav. 40, 358-366.

Wisniewski, A. B., Kirk, K. D., and Copeland, K. C. (2008). Longterm psychosexual development in genetic males affected by disorders of sex development (46,XY DSD) reared male or female. Curr. Pediatr. Rev. 4, 243-249.

Witelson, S. F., Kigar, D. L., Scamvougeras, A., Kideckel, D. M., Buck, B., Stanchev, P. L., Bronskill, M., and Black, S. (2008). Corpus callosum anatomy in right-handed homosexual and heterosexual men. Arch. Sex. Behav. 37, 857-863.

Woodley, S. K., and Baum, M. J. (2004). Differential activation of glomeruli in the ferret's main olfactory bulb by anal scent gland odours from males and females: an early step in mate identification. Eur. J. Neurosci. 20, 1025-1032.

Woodson, J. C., Balleine, B. W., and Gorski, R. A. (2002). Sexual experience interacts with steroid exposure to shape the partner preferences of rats. Horm. Behav. 42, 148-157.

Yokota, Y., Kawamura, Y., and Kameya Y. (2005). "Callosal shapes at the midsagittal plane: MRI differences of normal males, normal females, and GID," in 27th Annual Conference of the Engineering in Medicine and Biology Society, Shanghai, 3055-3058.

Zenchak, J. J., Anderson, G. C., and Schein, M. W. (1981). Sexual partner preference of adult rams (Ovis aries) as affected by social experiences during rearing. Appl. Anim. Ethol. 7, 157-167.

Zhou, J. N., Hofman, M. A., Gooren, L. J., and Swaab, D. F. (1995). A sex difference in the human brain and its relation to transsexuality. Nature 378, 68-70.

Conflict of Interest Statement: The authors declare that the research was conducted in the absence of any commercial or financial relationships that could be construed as a potential conflict of interest.

Received: 30 July 2011; paper pending published: 14 August 2011; accepted: 12 September 2011; published online: 03 October 2011.

Citation: Alexander BM, Skinner DC and Roselli CE (2011) Wired on steroids: sexual differentiation of the brain and its role in the expression of sexual partner preferences. Front. Endocrin. 2:42. doi: 10.3389/fendo.2011.00042

This article was submitted to Frontiers in Neuroendocrine Science, a specialty of Frontiers in Endocrinology.

Copyright (C) 2011 Alexander, Skinner and Roselli. This is an open-access article subject to a non-exclusive license between the authors and Frontiers Media $S A$, which permits use, distribution and reproduction in other forums, provided the original authors and source are credited and other Frontiers conditions are complied with. 